https://doi.org/10.14211/regepe.v8i1.867

\title{
COMPRAS PÚBLICAS E DESENVOLVIMENTO LOCAL: MICRO E PEQUENAS EMPRESAS LOCAIS NAS LICITAÇÕES DE UMA UNIVERSIDADE PÚBLICA MINEIRA
}

Recebido: 27/02/2018

Aprovado: 22/08/2018

\author{
${ }^{1}$ Fernanda Rodrigues Drumond Chaves \\ ${ }^{2}$ André Luís Bertassi \\ ${ }^{3}$ Gustavo Melo Silva
}

\section{RESUMO}

As aquisições de bens e serviços realizadas pelo Estado desempenham papel fundamental para o funcionamento da máquina pública na efetividade de políticas e funções assumidas pelo setor público. Dentro deste contexto, não se pode negar o relevante papel das micro e pequenas empresas (MPEs) nas economias nacionais. $O$ Estado pode utilizar o seu poder de compras para fomentar e desenvolver esse segmento da economia, criando políticas públicas de favorecimento às MPEs nas licitações governamentais. Nesse sentido, o objetivo do presente estudo foi analisar a influência das MPEs locais e regionais nos certames licitatórios de uma universidade pública mineira, no período de 2015 a 2017. A pesquisa exploratória e descritiva foi operacionalizada com dados coletados em fontes secundárias públicas e sistematizados por meio de estatística descritiva. Os resultados da pesquisa indicam que, apesar da ocorrência de aumento significativo do número de MPE contratadas com a administração pública, as locais representavam menos de $1 \%$ do total de compras da organização pública investigada. Concluiu-se que as lacunas existentes na legislação que tratam das prerrogativas concedidas às MPEs nas contratações governamentais geram dificuldades na aplicabilidade de tais benefícios, tornando a utilização da licitação como instrumento de política pública complexo. Os resultados indicam necessidade de avanços normativos e de intensificação nas pesquisas sobre a utilização do poder de compra do Estado como potencial indutor de desenvolvimento regional e local.

Palavras-chave: Compras Governamentais. Desenvolvimento Local. Micro e Pequena Empresa.

\footnotetext{
${ }^{1}$ Mestranda pelo Programa de Mestrado Profissional em Administração Pública (PROFIAP). E-mail: drumond.fernanda@ufsj.edu.br Orcid id: https://orcid.org/0000-0002-7068-7309

2Doutor em Administração pela Universidade Metodista de Piracicaba - UNIMEP, São Paulo, (Brasil). E-mail: bertassi@ufsj.edu.br Orcid id: https://orcid.org/0000-0002-5423-4465

${ }^{3}$ Doutor em Sociologia pela Universidade Federal de Minas Gerais - UFMG, Minas Gerais, (Brasil). E-mail: gustavomelo@ufsj.edu.br Orcid id: https://orcid.org/0000-0001-6431-1594
} 


\title{
PUBLIC PURCHASES AND LOCAL DEVELOPMENT: MICRO AND SMALL LOCAL COMPANIES IN THE BIDDING OF A PUBLIC UNIVERSITY IN MINAS GERAIS
}

\begin{abstract}
The acquisitions of goods and services carried out by the State play a fundamental role for the functioning of the public machine in the effectiveness of policies and functions assumed by the public sector. Within this context, the relevant role of micro and small enterprises (SMEs) in national economies cannot be denied. The State can use its purchasing power to foster and develop this segment of the economy by creating public policies to favor SMEs in government bids. In this line, the objective of the present study was to analyze the influence of local and regional SMEs in the bidding events of a public university in Minas Gerais, from 2015 to 2017. The exploratory and descriptive research was operationalized with data collected in public secondary sources and systematized through statistics descriptive. The results of the survey indicate that, despite a significant increase in the number of SMEs contracted with public administration, local companies represented less than $1 \%$ of the total purchases of the public organization under investigation. It was concluded that the existing gaps in the legislation dealing with the prerogatives granted to SMEs in government hiring generate difficulties in the applicability of such benefits, making the use of bidding as a complex public policy instrument. The results indicate the need for normative advances and intensification in the research on the use of the purchasing power of the State as a potential inducer of regional and local development.
\end{abstract}

Keywords: Government Purchases. Local Development. Micro and Small Enterprises. 


\section{INTRODUÇÃO}

O tema "compras governamentais" ganha relevância econômica devido ao grande volume de capital movimentado em todo o mundo. Os montantes de recursos envolvidos são expressivos. Estudos mostram que as compras públicas na Europa e nos Estados Unidos podem representar $16 \%$ e $20 \%$ do Produto Interno Bruto (PIB), respectivamente (Auriol, 2006; Dimitri, Piga, \& Spagnolo, 2006; OECD, 2002, 2017).

Dentro desse contexto, não se pode negar o relevante papel das MPEs nas economias nacionais, seja pelo seu peso na geração e manutenção de empregos, seja pela sua participação na composição do PIB. Estudo do Serviço Brasileiro de Apoio às Micro e Pequenas Empresas (SEBRAE), sobre a participação das microempresas (ME) e empresas de pequeno porte (EPP) na economia brasileira, mostra que elas respondem por aproximadamente $27 \%$ do PIB e $52 \%$ da ocupação formal (SEBRAE, 2014).

A política de uso do poder das compras públicas para desenvolver as MPEs não é novidade nas administrações de outros países (United States, 2005; União Europeia, 2014; Fonseca, \& Mota; 2016; Jacoby Fernandes, 2017). Trata-se, portanto, de prática já experimentada em alguns Estados para desenvolver economias locais e, por consequência, a economia nacional. O Estado brasileiro também tem seguido essa tendência, promovendo iniciativas para fomentar e desenvolver esse segmento da economia, sobretudo por intermédio de políticas que viabilizem o acesso ao crédito e ampliem a competitividade dessas organizações. Importante destacar que há um especial tratamento a essa parcela de empresas com sede constitucional, conforme Artigos 170, incisos X e 179 da Constituição da República Federativa do Brasil (CF/88) (Brasil, 1988).

Para tanto, uma das ferramentas criadas no Brasil é a Lei Complementar 123, de 14 de dezembro de 2006, e suas alterações. Ela estabelece tratamento diferenciado e favorecido às MEs e EPPs, inclusive no que tange à participação em licitações públicas.

Diante da importância que as Instituições Federais de Ensino Superior (IFES) vêm assumindo no desenvolvimento regional, sendo consideradas como um elemento-chave no processo (Kureski, \& Rolim, 2009), aliado ao relevante papel desempenhado pelas MPEs na economia nacional, apresenta-se a seguinte questão: Qual é a representatividade dos fornecedores locais no volume total de compras de uma Instituição Federal de Ensino Superior (IFES) localizada no interior de Minas Gerais?

Para a análise do problema proposto, são considerados o objetivo geral e os específicos. O primeiro consiste em analisar a influência das MEs e EPPs locais nos 
certames licitatórios de uma universidade pública mineira. Como objetivos específicos, a pesquisa se propõe a: i) verificar o universo das MEs e EPPs homologadas nos pregões eletrônicos realizados pela IFES pesquisadas entre 2015 e 2017; e ii) recortar, deste universo, as MEs e EPPs localizadas na microrregião onde está situada a universidade lócus do estudo.

Neste ponto, cumpre ressaltar que a escolha da IFES em análise justifica-se pelo fato de uma pesquisadora, dentre os demais, ser integrante do quadro efetivo de servidores da universidade, lotada no Setor de Compras e Licitações, atuando como pregoeira da instituição há mais de quatro anos.

O trabalho se divide em quatro seções, além desta introdução. Na seção 2, apresenta-se o arcabouço teórico do estudo, o qual é subdivido em cinco momentos. Inicialmente é abordada a relação Estado x Mercado sob a perspectiva das compras públicas. Num segundo momento, demonstra-se a influência das compras governamentais na economia nacional e de outros países, para posteriormente tratar-se dos procedimentos que regem as contratações públicas do Brasil e do mundo. $\mathrm{Na}$ sequência é dado enfoque ao uso do poder de compra do Estado em prol do desenvolvimento socioeconômico. No quinto e último momento aborda-se as ME e EPP, especialmente no que tange às prerrogativas concedidas a este segmento de empresas nas licitações públicas brasileiras. A seção 3 apresenta a metodologia utilizada para o desenvolvimento desta pesquisa. A quarta seção expõe os resultados obtidos e a análise dos dados e por fim, os autores apresentam as conclusões do estudo.

\section{RELAÇÕES ENTRE ESTADO E MERCADO: COMPRAS PÚBLICAS E DESENVOLVIMENTO LOCAL}

\subsection{A Relação Estado x Mercado e as Compras Públicas}

A origem das aquisições de bens é marcada pelas relações de troca estabelecidas pelo homem quando este percebeu que poderia entregar o produto de seu trabalho e receber em troca o produto de outro trabalho que fosse equivalente. Ao longo da história, tais relações foram evoluindo até se chegar à economia mercantil, considerada o primeiro estágio do capitalismo e das estruturas do Estado (Vacca, 1991).

Nesse contexto, o desenvolvimento das técnicas de produção, sobretudo na Revolução Industrial, modificou o eixo econômico e criou novas dinâmicas sociais, transformando a economia mercantil em economia de produção. O homem passou a 
produzir mais do que o necessário para a própria subsistência, com o intuito de acumular capital.

Assim, ao final do século XVIII, o mercado deixa de ser apenas cenário das relações de troca e não é mais o principal instrumento de legitimação da ordem social e política existentes (Vacca, 1991).

Com o aumento crescente da produção em massa e da urbanização, tornou-se cada vez mais imprescindível incumbir novas atribuições ao governo. Assim, a máquina do Estado surge, assumindo, além de outras funções, a de reguladora do ciclo econômico.

Além da ativa atuação no sistema econômico, o Estado vinha desenvolvendo, desde o final do século XIX, novas relações com a sociedade civil, conforme expõe Ouverney (2005), resultando na formação e posterior consolidação de sistemas de proteção social que, não obstante a diversidade de formas assumidas nos diferentes contextos nacionais, convencionou-se chamar de Estado do Bem-Estar Social (Welfare State).

A partir daí houve maior estreitamento da relação público-privado. A maior complexidade das demandas da sociedade exigiu a viabilização, pelo Estado, da atuação de particulares na realização de negócios comuns (Araújo, 2011). Assim, o Estado deixa de ser autossuficiente, no que tange ao atendimento dos interesses públicos, necessitando socorrer-se ao mercado, contratando particulares para auxiliarem o aparelho estatal a suprir as demandas da sociedade.

As compras públicas são, por sua vez, fruto desse entrelaçamento entre público e privado. Atualmente, as aquisições de bens e serviços realizadas pelo Estado, seja para o bom funcionamento da máquina pública, seja para viabilizar políticas e funções assumidas pelo setor público, diante da complexidade e demandas sociais, impactam, significativamente, as despesas públicas.

\subsection{O Cenário das Compras Públicas na Economia Mundial e Nacional}

O tema "compras governamentais" ganha importância devido ao grande volume de capital movimentado em todo o mundo. Segundo Auriol (2006), as compras do setor público de bens e serviços podem representar mais de 18\% do PIB mundial. Em 2002 esse valor foi estimado em US\$ 5,8 trilhões. Neste mesmo ano, um estudo realizado pela Organisation for Economic Co-operation and Development (OECD) estimou que, em 1998, o volume total das aquisições governamentais foi de $\bigcup \$ 5,55$ trilhões, ou seja, 
o equivalente a $82,3 \%$ de todo o volume de transações de bens e serviços ocorridos no mundo naquela época (OECD, 2002).

Em números atualizados, o relatório Government at a Glance 2017 (OECD, 2017) publicou dados comprovando que, nos países membros da OECD, o tamanho total das compras públicas representa aproximadamente $12 \%$ do PIB nominal, fazendo desse setor uma atividade econômica chave: varia de 5,1\% no México para 20,2\% na Holanda.

A Figura 1 a seguir discrimina, em percentuais, os valores de comprometimento do PIB com compras governamentais de todos os países-membros da OECD em 2007, 2009 e 2015.

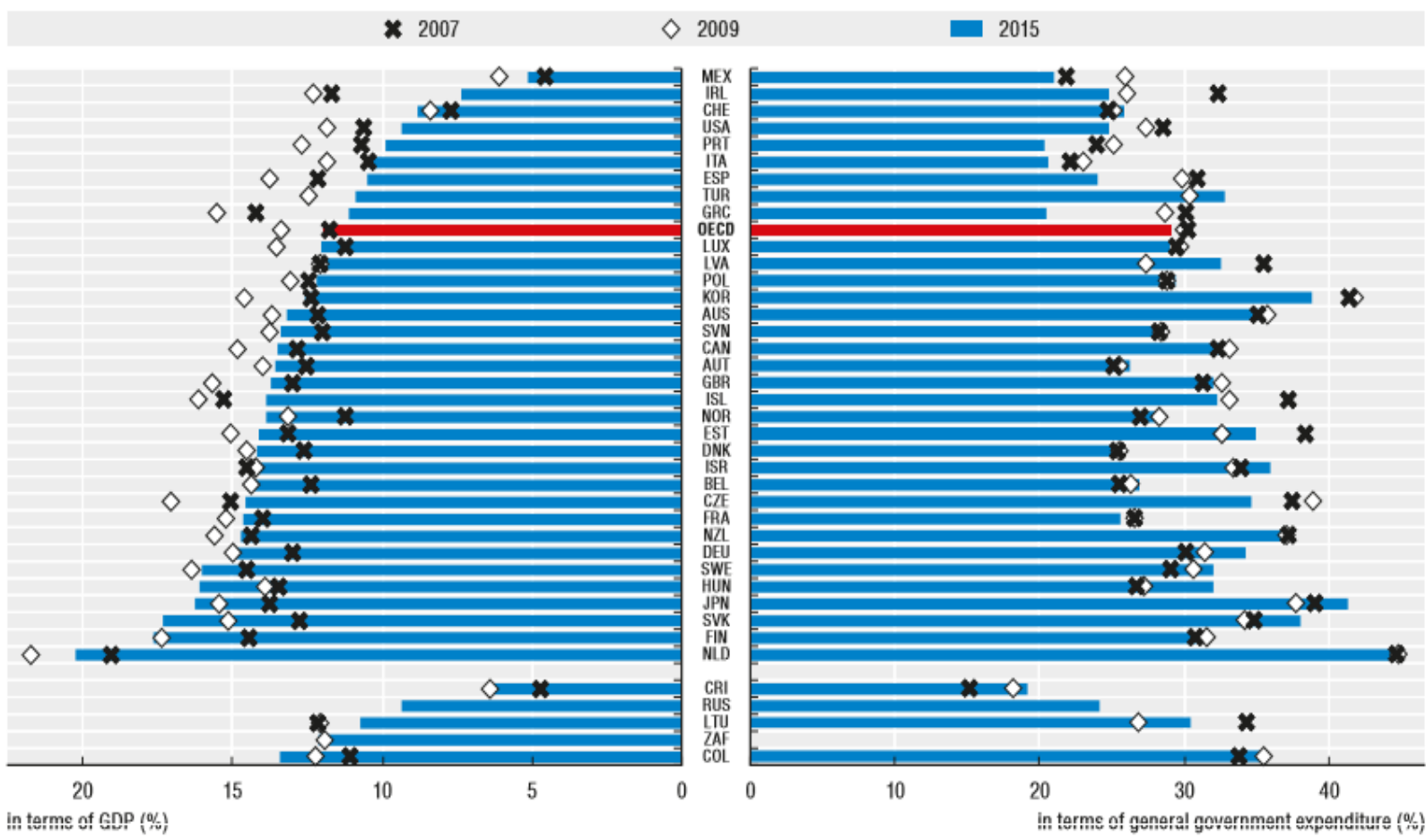

Figura 1: Despesas de compras do governo federal como porcentagem do PIB e despesas públicas totais, 2007, 2009 e 2015

Fonte: OECD. (2017).

Ainda no documento supracitado, a OECD destaca que, além da observância aos princípios e às regras que norteiam as compras públicas, os governos estão dedicando esforços para aumentar a eficiência e eficácia dessa função chave do Estado.

From identifying the needs, determining the person or organization to supply them; to ensuring delivery of purchases, within the agreed timeframe and to the expected quality, public procurement has implications for public sector performance and citizen's satisfaction (OECD, 2017, p. 172). ${ }^{4}$

4 Desde identificar as necessidades, determinando a pessoa ou organização para fornecê-las; garantir a entrega das compras, dentro do prazo acordado e com a qualidade esperada, os contratos

Revista de Empreendedorismo e Gestão de Pequenas Empresas | v.8 | n.1 | p. 77-101 | Jan/Abr. 2019. 
Os contratos públicos eficientes e eficazes são, portanto, essenciais para responder às necessidades dos cidadãos, posicionando-se cada vez mais como um pilar fundamental da boa governança e ajudando a restaurar a confiança no setor público.

No que tange às contratações públicas no Brasil, o relatório Informações Gerenciais de Contratações e Compras Públicas, publicado pelo Ministério do Planejamento, Orçamento e Gestão (Brasil, 2014), atualmente denominado Ministério do Planejamento, Desenvolvimento e Gestão, estimou que, entre janeiro e dezembro de 2014, as compras governamentais movimentaram $\mathrm{R} \$ 62,1$ bilhões na aquisição de bens e serviços por meio de 196,9 mil processos, levando-se em consideração todas as modalidades de contratação. Em busca feita ao Painel de Compras do Governo Federal (Brasil, 2017a), ferramenta criada pelo Ministério do Planejamento, por meio de sua Secretaria de Gestão (SEGES), o valor das contratações, em 2016, exibiu o montante de 50,9 bilhões para o período, representando em torno de $8 \%$ do PIB nacional. A partir dos dados apresentados, percebe-se que as compras públicas guardam forte relação com a ação do Estado capaz de ativar dispositivos para dinamizar a economia nacional, uma vez que movimentam recursos que representam parcela significativa do PIB brasileiro.

Importante destacar que cada Estado possui um regramento específico a fim de regular seu sistema de contratações, composto de princípios, normas e procedimentos que irão indicar o nível de flexibilidade ou rigidez da gestão de compras governamentais de cada um.

\subsection{Procedimentos que Regem as Contratações Públicas no Brasil e no Mundo}

Partindo-se da análise do sistema de compras públicas em nível internacional, na União Europeia, a legislação que trata das compras governamentais desse bloco econômico é regida por meio de Diretivas, que são ordenamentos estabelecendo a coordenação de normas e procedimentos para as aquisições de bens e contratações de serviços e obras públicas, a partir de determinado valor mínimo. Os países membros devem adaptar sua legislação nacional com base nas Diretivas, aplicando os princípios de livre circulação de bens, tratamento nacional e não discriminação, e transparência (Torres, 2012; União Europeia, 2014).

Já no Estado norte-americano, tem-se adotado atualmente uma política que veio a se tornar o exemplo mais completo de utilização do poder de compra de um país para a obtenção de resultados de política econômica e social (Moreira, \& Morais, 2003;

públicos têm implicações para o desempenho do setor público e para a satisfação dos cidadãos (OECD, 2017, p. 172, tradução nossa).

Revista de Empreendedorismo e Gestão de Pequenas Empresas | v.8 | n.1 | p. 77-101 | Jan/Abr. 2019. 
Oliveira, 2015). Lá não existe uma legislação de caráter nacional que estabeleça o processo de aquisição para todos os entes federativos. Ao contrário, cada ente possui independência para definir sua própria regulamentação. No plano federal, o regulamento que rege as compras públicas é o Federal Acquisition Regulation (FAR). Entretanto, cada agência pode desenvolver seus próprios regulamentos de compra, que serão aplicados em conjunto com o FAR, mas sem conflitos.

Os objetivos dos EUA são elencados em uma coletânea de políticas públicas que abrangem aspectos econômicos, industriais, sociais, militares e valorização do desenvolvimento local, este último aspecto baseado na determinação de que os órgãos e empresas públicas concedam preferência, nas suas aquisições, aos bens de produção doméstica, de acordo com condições e exigências estabelecidas nas normas e procedimentos de compras governamentais (Torres, 2012; United States, 2005). Salienta-se aqui que a promoção do desenvolvimento nacional é objetivo comum expresso na legislação que regulamenta as licitações públicas brasileiras, conforme será exposto adiante.

O pensamento de Gansler, Lucyshyn e Ross (2003, p. 6) evidenciam que o governo norte-americano está "[...] increasingly integrating private sector services into its operations. The challenge is to adapt these practices and integrate these services in ways that will produce the overall greatest results, not just optimize selected elements of the supply chain"

Diferentemente do que ocorre nos EUA e em outros países do mundo, as aquisições públicas federais brasileiras não estão seguindo a tendência de buscar inspiração nos desenvolvimentos privados, a preocupação ainda se restringe ao cumprimento estrito do rito legal.

Motta (2010) corrobora com essa ideia ao afirmar que:

Como a legislação brasileira em vigor é fruto de uma preocupação primordial com o combate à corrupção, sendo ainda combinada com o princípio jurídico da legalidade, na prática, qualquer outra dimensão, além do cumprimento do rito legal, que se queira perseguir em termos de melhora da qualidade das aquisições, torna-se irrelevante. Os riscos pessoais a que se submetem os agentes públicos responsáveis pelas aquisições é de tal monta que dificulta o surgimento e implementação de inovações (Motta, 2010, p. 109).

No caso brasileiro, a discussão em torno das questões relacionadas com as compras governamentais tende a se centrar basicamente nos aspectos jurídicos dos

5 "[...] integrando cada vez mais os serviços do setor privado em suas operações. O desafio é adaptar essas práticas e integrar esses serviços de maneira a produzir os melhores resultados, não apenas otimizar os elementos selecionados da cadeia de suprimento". (Gansler, Lucyshyn e Ross (2003, p. 6, tradução nossa).

Revista de Empreendedorismo e Gestão de Pequenas Empresas | v.8 | n.1 | p. 77-101 | Jan/Abr. 2019. 
procedimentos, ainda que a administração pública seja regida pelo princípio constitucional da eficiência ${ }^{6}$.

Motta (2010) acrescenta, ainda, que o eventual sacrifício da eficiência/eficácia em nome do combate à corrupção, não vem surtindo os efeitos esperados. Mesmo organizações internacionais como o Banco Mundial que, via de regra, orienta os países em desenvolvimento que elaborem legislações de compras públicas mais transparentes, permitindo o controle e o combate à corrupção, apontam que no caso brasileiro, "[...] the transparency of the 1993 procurement law provided an adequate legal framework to combat corrupt and fraudulent practices, but this has not been enough to their eradication"7 (World Bank, 2004, p. xii).

A legislação brasileira, sobre compras governamentais, está consolidada na Lei $n^{\circ}$ 8.666, de 21 de junho de 1993, e suas alterações posteriores. A referida lei estabelece as normas gerais sobre licitações e contratos administrativos pertinentes a obras, serviços, inclusive de publicidade, compras, alienações e locações no âmbito dos poderes da União, dos estados, do Distrito Federal e dos municípios (Brasil, 1993), sendo, portanto, de aplicação obrigatória para os órgãos da administração pública direta e indireta de todos os entes federados.

Fiuza (2009) destaca que a Lei de Licitações estabelece ritos licitatórios comuns e bastante formais entre organizações de diferentes naturezas, portes e realidades, eliminando qualquer flexibilidade ao gestor, sendo amplamente considerada um arcabouço legal rigoroso.

O autor sugere, ainda, que os focos das compras deveriam ser outros, os quais vão de encontro aos preceitos adotados internacionalmente, tais como: quais são os resultados esperados com a contratação? Quais são os objetivos do comprador? Quais são as condições de mercado para se comprar o que se pretende?

A exigência de licitação nas aquisições públicas de bens e serviços baseia-se em princípios constitucionais, elencados no Art. 37, caput, da Carga Magna, in verbis:

A administração pública direta e indireta de qualquer dos Poderes da União, dos Estados, do Distrito Federal e dos Municípios obedecerá aos princípios de legalidade, impessoalidade, moralidade, publicidade e eficiência [...] (Brasil, 1988)

Além dos princípios expressos na $\mathrm{CF} / 88$, as licitações são regidas, ainda, por princípios específicos elencados na Lei 8.666/93, quais sejam:

\footnotetext{
${ }^{6} \mathrm{CF} / 88$, Art. 39, caput, com a redação da Emenda Constitucional n. ำ 19/98.

7 "[...] a transparência da lei de aquisições de 1993 proporcionou uma estrutura legal adequada para combater práticas corruptas e fraudulentas, mas isso não foi suficiente para sua erradicação" (Banco Mundial, 2004, p. Xii).
}

Revista de Empreendedorismo e Gestão de Pequenas Empresas | v.8 | n.1 | p. 77-101 | Jan/Abr. 2019. 
Art. 3o A licitação destina-se a garantir a observância do princípio constitucional da isonomia, a seleção da proposta mais vantajosa para a administração e a promoção do desenvolvimento nacional sustentável e será processada e julgada em estrita conformidade com os princípios básicos da legalidade, da impessoalidade, da moralidade, da igualdade, da publicidade, da probidade administrativa, da vinculação ao instrumento convocatório, do julgamento objetivo e dos que lhes são correlatos. (grifos nossos). (Brasil, 1993).

Destaca-se, dentre aqueles expressos na Lei de Licitações, o princípio do desenvolvimento nacional sustentável, podendo-se inferir, portanto, que a lei intenciona que as compras públicas privilegiem os produtos manufaturados e os serviços nacionais que atendam às normas técnicas brasileiras, pretendendo, assim, incentivar o fortalecimento da indústria nacional e o fomento ao setor de serviços.

Neste ponto, cumpre ressaltar que a CF/88 já estabelecia proteções e preferências em vários aspectos às MPEs, conforme será visto adiante.

\title{
2.4 O Uso do Poder de Compra do Estado como Instrumento de Política Pública de Desenvolvimento Socioeconômico
}

Frente à expressiva representatividade do volume de capital envolvido nas compras públicas, o Estado pode se valer do seu poder de compra, atribuindo, além da função econômica, uma função social para a demanda de bens e serviços, em que a economicidade das compras públicas deixa de ser fator exclusivo de ponderação para ser compartilhado com os objetivos maiores de desenvolvimento econômico sustentável, geração de emprego e renda e erradicação da pobreza (Câmara, \& Frossard, 2010; Freitas, 2011; Sousa Junior, 2008).

Seguindo a definição de poder de compra do Ministério do Desenvolvimento, Indústria e Comércio (MDIC):

\begin{abstract}
O poder de compra significa o poder do consumidor, seja ele empresa privada, órgão público, cooperativa ou pessoa física, que ao adquirir bens e serviços define suas exigências e necessidades, tornando-se um indutor da qualidade, da produtividade e de inovação tecnológica, gerando emprego, ocupação e renda, contribuindo para a competitividade e desenvolvimento do país (Brasil, apud Arantes, 2006, p. 25).
\end{abstract}

Portanto, o poder de compra do Estado revela duas outras funções, que vão além da visão simplista de atividade-meio dada às contratações públicas, passando a assumir as funções econômica e social. Este é o entendimento da licitação como instrumento de políticas públicas (Arantes, 2006; Baradel, 2011; Silva, 2008; Sousa Junior, 2008).

Em nível internacional, destaca-se os Estados Unidos da América (EUA) como referência de larga utilização do poder de compra do Estado como política de 
desenvolvimento industrial. As diretrizes para as compras e contratações de bens, serviços, construções e obras públicas dos EUA estão previstas na FAR, conforme exposto anteriormente. Nela também estão consolidados a política e os procedimentos que asseguram preferência nas contratações governamentais para as small business. Os dispositivos estão previstos na seção 19.000 da FAR e têm como base as determinações expressas em três programas: o Small Business Program, voltado às pequenas empresas; o Buy American Act, que restringe as aquisições de produtos estrangeiros para uso interno nos Estados Unidos; e o Balance of Payments Program, que regulamenta as aquisições dos Estados Unidos para utilização no exterior (Moreira, \& Morais, 2003; United States, 2005).

Como se pode observar, o uso do poder de compra para fortalecer as MPEs não é novidade. Ao contrário, trata-se de prática já experimentada em outros países (Fonseca \& Mota, 2016; União Europeia, 2014; United States, 2005) para desenvolver economias locais e, por consequência, promover o desenvolvimento nacional.

O Estado brasileiro também tem seguido essa tendência, criando iniciativas para fomentar e desenvolver esse segmento da economia, tendo sede constitucional, conforme artigo 170, inciso X e artigo 179 da Carta Magna (Brasil, 1988). Essa proteção foi realizada através de Lei Complementar, como determina o artigo 146, inciso III, alínea "d" da Constituição, sendo tais benefícios materializados com o advento da Lei Complementar $n^{\circ} 123$, de 14 de dezembro de 2006, instituída como Estatuto Nacional da Microempresa e da Empresa de Pequeno Porte e suas alterações (Brasil, 2006).

\subsection{As Microempresas e Empresas de Pequeno Porte nas Licitações Públicas Brasileiras}

De acordo com o SEBRAE (Jacoby Fernandes, 2017; SEBRAE, 2014), as MEs e EPPs vêm adquirindo, ao longo dos últimos 30 anos, uma importância crescente no país, pois é inquestionável o relevante papel socioeconômico desempenhado por estas empresas.

Em 1985, o IBGE calculou em 21\% a participação dos pequenos negócios no PIB. Já em 2001, o percentual cresceu para 23,2\% e em 2011, atingiu 27\%. Ou seja, mais de um quarto do Produto Interno Bruto brasileiro é gerado pelos pequenos negócios (SEBRAE, 2014).

Tendo em vista a expansão das MPEs, houve a necessidade de regulamentação específica para garantir sua permanência no mercado. Instituiu-se, conforme disposto anteriormente, a Lei Complementar n. 123/2006, alterada, posteriormente, pela Lei Complementar 147, de 07 de agosto de 2014, a qual prevê tratamento diferenciado que 
venha favorecer as MEs e EPPs, tendo como estratégia a geração de empregos, a melhor distribuição de renda, a promoção da inclusão social, a redução da informalidade e o fortalecimento da economia (Freitas, 2011; Jacoby Fernandes, 2017).

No âmbito da administração pública federal, especificamente, o Decreto $n^{\circ} 6.204$, de 05 de setembro de 2007, posteriormente revogado pelo Decreto 8.538, de 6 de outubro de 2015, veio regulamentar o tratamento favorecido, diferenciado e simplificado dispensado às MEs e EPPs nas contratações públicas federais de bens, serviços e obras. As prerrogativas concedidas às MPEs possuem como objetivos, conforme disposto no Art. $1^{\circ}$ do referido Decreto: “[...] i) promover o desenvolvimento econômico e social no âmbito local e regional; ii) ampliar a eficiência das políticas públicas; e iii) incentivar a inovação tecnológica" (grifos nossos) (Brasil, 2015).

Dentre os benefícios garantidos às MPEs, destacam-se principalmente: a) a regulamentação fiscal tardia; b) a realização de licitações exclusivas para ME e EPP nas contratações de até $R \$ 80$ mil; e c) a regulamentação da possibilidade de reservar, para essas empresas, até $25 \%$ do valor das contratações de bens e serviços. A LC 123/2006 prevê, ainda, que em licitações de valor superior a $\mathrm{R} \$ 80$ mil, os órgãos contratantes podem exigir a subcontratação de empresas de menor porte. No caso de empate em licitações pelo critério de menor preço, a preferência será das MEs e EPPs (Brasil, 2006; Cabral, Reis, \& Sampaio, 2015).

Clark III e Moutray (2004), ao analisarem o futuro das small business no mercado de compras públicas americano, afirmam que esse setor oferece oportunidades valiosas para as pequenas empresas, pois ao terem acesso a esse mercado, têm condições de crescer. Consideram ainda que as MPEs têm contribuições importantes a oferecer, e destacam que garantir que o mercado das contratações públicas permaneça aberto para as pequenas empresas é um desafio constante.

Contudo, estudos demonstram que nem sempre as MPEs se consideram aptas ou motivadas a concorrerem nos certames públicos (Cabral et al., 2015; Carneiro, 2017; Fee, Erridge, \& Hennigan, 2002; Karjalainen, \& Kemppainen, 2008; Reis, \& Cabral, 2015). A pesquisa feita por Fee et al. (2002) destacou alguns problemas enfrentados pelas MPEs na Europa que são as principais barreiras para a participação das MEs e EPPs nas contratações governamentais: a documentação onerosa, o tempo e o custo envolvidos na preparação de ofertas e a especificação de normas.

Karjalainen e Kemppainen (2008) acrescentam que a própria natureza das concorrências públicas, normalmente caracterizadas por maiores exigências e 
formalismos por conta das regras de accountability, pode contribuir para o afastamento de MPEs em processos de aquisição do setor público.

\section{PROCEDIMENTOS METOdOLÓGICOS}

\subsection{Caracterização da Pesquisa}

A metodologia desenvolvida no presente estudo baseou-se em uma abordagem qualitativa com aporte quantitativo. Theóphilo e Martins (2009) destacam a importância da integração na pesquisa mista e explicam que os limites da pesquisa qualitativa podem ser contrabalanceados pelo alcance da quantitativa e vice-versa. Segundo os autores, as duas abordagens não devem ser percebidas como opostas, mas sim como complementares.

Quanto à temporalidade, a pesquisa classifica-se como transversal (ou seccional), tendo em vista que o recorte temporal foi determinado por um período definido, em um momento específico. Neste ponto, destaca-se que o recorte temporal foi definido a partir da disponibilidade de informações encontradas nos sítios eletrônicos consultados ${ }^{8}$.

Em se tratando da natureza dos objetivos metodológicos, a pesquisa caracteriza-se como descritiva e exploratória. O elemento descritivo é percebido, pois o estudo busca especificar propriedades, características e traços importantes do fenômeno analisado, descrevendo, assim, tendências de um grupo ou população (Sampieri, Collado, \& Lucio, 2013).

Verifica-se também a presença de características exploratórias em razão de haver um problema de pesquisa pouco estudado, sobre o qual ainda existem muitas dúvidas (Sampieri et al., 2013).

\subsection{População e Amostra}

A população de uma pesquisa científica, segundo Seltiz et al. (1980, apud Sampieri et al., 2013, p. 193), é formada a partir do "conjunto de todos os casos que preencham uma série de especificações".

Assim, a população da presente pesquisa foi formada pelos pregões eletrônicos realizados pela instituição investigada no período analisado e que tiveram ME ou EPP como participantes. Acrescenta-se, ainda, que as análises foram limitadas apenas à modalidade "pregão eletrônico", tendo em vista que representou, no período de 2015 a

\footnotetext{
${ }^{8}$ No website do Setor de Compras do órgão investigado estavam disponíveis para consulta apenas informações de 2015 a 2018, então optou-se por levantar os dados de exercícios financeiros já encerrados, quais sejam: de 2015 a 2017.
}

Revista de Empreendedorismo e Gestão de Pequenas Empresas | v.8 | n.1 | p. 77-101 | Jan/Abr. 2019. 
2017, segundo o Painel de Compras do Governo Federal (Brasil, 2017a), 94\% dos processos licitatórios realizados pela instituição.

A amostragem, por sua vez, foi composta por um subconjunto da população (Theóphilo, \& Martins, 2009) e classifica-se como não probabilística e intencional, constituída pelas licitações que apresentaram uma ou mais ME ou EPP homologadas. Assim, dentre os 294 pregões eletrônicos publicados pela instituição pesquisada, entre 2015 e 2017, foram selecionados 161 certames que apresentavam as seguintes características: a) tinham como objeto material ou serviço comum para suprir necessidades de algum dos campi do município sede da universidade; e b) continham algum item homologado para ME ou EPP, validando-se, desta forma, a amostra.

\subsection{Técnicas e Instrumentos de Coleta e Análise de Dados}

Como técnicas de coleta de dados, utilizou-se a pesquisa bibliográfica e o levantamento documental. A primeira subsidiou o desenvolvimento da perspectiva teórica, o que implica, segundo Rojas (2002, apud Sampieri et al., 2013, p. 75), "expor e analisar as teorias, as conceituações, as pesquisas prévias e os antecedentes em geral que sejam considerados válidos para o correto encaixe do estudo".

O levantamento documental foi feito diretamente pelos pesquisadores, por meio de fontes secundárias públicas e os dados coletados dos sítios eletrônicos da universidade investigada do Portal de Compras do Governo Federal (Compras Governamentais) e do Sistema de Cadastro Unificado de Fornecedores (SICAF), este último gerido pela Secretaria de Gestão do Ministério do Planejamento, Desenvolvimento e Gestão.

Para atingir os objetivos específicos, incialmente foi consultado o sítio eletrônico Compras Governamentais (Brasil, 2017b) e, por meio dos documentos "Ata do Pregão" e "Resultado por Fornecedor" lá disponíveis, extraiu-se os dados apenas das licitações que apresentavam as características para composição da amostra. Os dados levantados foram: número do pregão; objeto da licitação; classificação quanto a material permanente, consumo ou serviço; CNPJ das MEs ou EPPs homologadas; e valor homologado por empresa.

A partir do levantamento das MEs e EPPs vencedoras no período, foi feita uma busca individualizada por CNPJ levantado, a fim de se obter dados referentes ao porte das empresas e localização de cada uma delas. Para tanto, utilizou-se como ferramenta de busca o SICAF, que constitui o registro cadastral do Poder Executivo Federal, mantido pelos órgãos e entidades que compõem o Sistema de Serviços Gerais (SISG). 
Assim, foram pesquisadas 641 empresas, de forma individual, nesta plataforma, para a obtenção do município e estado onde estão inseridas.

Por fim, os dados obtidos foram tabulados com a principal finalidade de se verificar, no período analisado, qual era o quantitativo de MPEs locais/regionais logradas vencedoras nos pregões promovidos pela IFES investigada. Destaca-se que a análise quantitativa dos dados foi feita por meio de estatística descritiva simples, com a utilização do software Microsoft Excel.

\section{LEVANTAMENTO E ANÁLISE DOS RESULTADOS}

Partindo para a análise dos dados, a Tabela 1 abaixo mostra o montante gasto com compras na IFES investigada, exclusivamente na modalidade pregão eletrônico, de 2015 a 2017, bem como os valores homologados para ME/EPP nas 161 licitações que tiveram como objeto a aquisição de bens ou serviços, para suprir as necessidades de algum dos campi do município sede do órgão.

Tabela 1: Valores homologados nos pregões eletrônicos no período 2015-2017

\begin{tabular}{ccc}
\hline Exercício financeiro / ano & Valor total das Compras ${ }^{*}$ & Valor homologado para ME/EPP $^{\star *}$ \\
\hline 2015 & $11.179 .434,30$ & $6.206 .671,46$ \\
2016 & $22.741 .816,85$ & $7.190 .996,54$ \\
2017 & $16.426 .195,22$ & $5.643 .519,87$
\end{tabular}

Fonte: Elaborada pelos autores (2018)

* Valores expressos em reais, referentes exclusivamente às licitações realizadas por meio da modalidade pregão eletrônico.

** Valores expressos em reais, referentes ao total de itens homologados para ME/EPP nos pregões eletrônicos que tiveram como objeto a aquisição de bens ou serviços para suprir as necessidades de algum dos campi do município sede do órgão.

A partir dos dados apresentados, depreende-se que os recursos despendidos com ME/EPP para atender as demandas de compras dos campi do município sede da IFES investigada, pode representar até $55 \%$ do total gasto com pregões realizados pelo órgão, expressos em um montante de aproximadamente 20 milhões de reais no período.

A princípio, esse cenário promove maior otimismo frente ao uso do poder de compra governamental em prol do desenvolvimento socioeconômico, à medida que o aumento no montante gasto com MPEs nas aquisições públicas contribui para que a visão tradicional que se tem desse setor (de atividade-meio) possa ser ampliada, a fim de apoiar ou estimular segmentos vulneráveis ou estratégicos da sociedade.

Câmara e Frossard (2010) acreditam nesse potencial e elucidam que, quando se fala em contratações públicas, deve-se ir além da dimensão econômica, avançando no sentido da finalidade da ação governamental. 
[...] é preciso intensificar as discussões sobre o potencial das compras realizadas pela administração pública brasileira, atribuindo novos significados ao gasto público a partir de suas compras. O volume de gastos dos entes públicos pode trazer impacto socioeconômico, servindo como um instrumento de destaque da ação governamental dado ao poder de compra do setor público (Câmara, \& Frossard, 2010, p. 11).

Assim, acredita-se que um maior incremento das MPEs nas compras públicas pode estimular o desenvolvimento econômico e social, em especial da economia local e de regiões com menor índice de desenvolvimento. Contudo, na prática, essa nem sempre é a realidade apresentada, conforme será demonstrado a seguir.

A Tabela 2 abaixo aponta dados referentes ao número de MPEs mineiras que obtiveram sucesso nos pregões analisados, a partir do universo de fornecedores homologados, ou seja, a representatividade das MEs e EPPs com sede em Minas Gerais (MG) que tiveram um ou mais itens homologados nos pregões realizados pela universidade pesquisada, entre 2015 e 2017.

Tabela 2: Fornecedores homologados nos pregões eletrônicos no período 2015-2017

\begin{tabular}{ccc}
\hline Exercício financeiro / ano & Total de fornecedores homologados* & ME/EPP localizadas em MG \\
\hline 2015 & 185 & 83 \\
2016 & 178 & 66 \\
2017 & 278 & 103 \\
\hline
\end{tabular}

Fonte: Elaborada pelos autores (2018)

* Empresas sediadas em qualquer parte do território nacional, enquadradas como ME ou EPP.

Com base nos dados apontados, verifica-se, de forma geral, um aumento de MPEs homologadas nos pregões eletrônicos realizados pelo órgão ao longo do período, o que gera um possível indício de que as iniciativas criadas pelo Estado, a fim de fomentar a participação desse segmento de empresas em licitações, podem estar surtindo o efeito esperado.

Esse resultado encontra-se em sintonia com o exposto por Cabral et al. (2015), cuja pesquisa demonstrou que as mudanças na legislação têm cumprido seu objetivo no sentido de facilitar o acesso das MPEs nas contratações do setor público. Neste ponto, cumpre ressaltar que não foi objeto de análise a relação entre as MEs e EPPs participantes e as efetivamente homologadas, a fim de verificar a taxa de sucesso das empresas que tentam concorrer nos certames do órgão.

No entanto, em que pese ter havido maior incremento de MPEs nas licitações do órgão, destaca-se que do total das MEs e EPPs vencedoras dos certames analisados, em média, apenas $40 \%$ estão situadas no estado de Minas Gerais, gerando uma possível contradição a um dos objetivos às prerrogativas concedidas para as MPEs, 
qual seja o da promoção ao desenvolvimento econômico e social no âmbito local e regional (Brasil, 2015).

A Tabela 3 a seguir mostra dados que ratificam a hipótese levantada anteriormente, comprovando, em uma análise ainda mais específica, a representatividade das MEs/EPPs locais/regionais nas contratações do órgão, no período.

Tabela 3: MPEs locais/regionais homologadas nos pregões eletrônicos no período 2015-2017

\begin{tabular}{cc}
\hline Exercício financeiro / ano & Total de ME/EPP localizadas na microrregião da sede da instituição* \\
\hline 2015 & 2 \\
2016 & 0 \\
2017 & 2
\end{tabular}

Fonte: Elaborada pelos autores (2018)

* O conceito de microrregião adotado para fins deste estudo é a região composta de municípios limítrofes à localidade da sede da universidade investigada, região esta delimitada pelo IBGE (Brasil, 2017c).

Os dados apontados na Tabela 3 demonstram, portanto, que a contribuição de ME/EPP locais/regionais nas contratações da universidade pesquisada mostra-se muito abaixo do esperado, durante o período. No ano de 2016, o cenário foi ainda mais grave, sendo nulo o sucesso de quaisquer MPEs localizadas na microrregião onde é situada a universidade lócus do estudo. Isso significa que, dentre os 724 itens homologados para ME/EPP, nos três anos avaliados, apenas 4 deles foram contemplados para MPE local ou regional, não atingindo o percentual de $1 \%$ de representatividade no todo.

Assim, ao relacionar os resultados apresentados nas Tabelas 2 e $3 \mathrm{com} 0$ arcabouço teórico trazido ao estudo, infere-se que a baixa adesão de pequenas empresas locais e regionais nas compras da universidade investigada pode impactar negativamente 0 desenvolvimento da região onde está inserida, tendo em vista que a atuação delas não chegou a $50 \%$ das empresas analisadas, e no âmbito da localidade da sede do órgão, praticamente não existiu. Ademais, este cenário pode provocar consequente comprometimento da relação "Estado x Mercado" estritamente necessária para o bom funcionamento da máquina pública.

Ademais, os resultados podem, ainda, ser reflexos das teses defendidas por alguns autores (Cabral et al., 2015; Carneiro, 2017; Fee et al., 2002; Karjalainen, \& Kemppainen, 2008; Reis, \& Cabral, 2015), de que nem sempre as MPEs consideram-se aptas ou motivadas a concorrerem nos certames públicos. O estudo desenvolvido por Moreira e Morais (2003, p. 129) corrobora ainda mais com esse entendimento:

[...] as pequenas empresas enfrentam obstáculos em todas as fases dos procedimentos de licitação, como: a falta de informação sobre contratos potenciais; a defasagem entre o valor das contratações e o tamanho da empresa; e a necessidade de cumprir as normas técnicas e as exigências de qualificação. 
A pesquisa desenvolvida por Cabral et al. (2015) mostrou que a ausência de competências das pequenas empresas tende a ser correlacionada ao desempenho insatisfatório delas nos certames licitatórios, e os autores concluíram que "o conjunto de competências presentes nas pequenas firmas pode influenciar seu acesso e as chances de sucesso em compras públicas" (Cabral et al., 2015, p. 488).

Ainda na mesma seara, surge uma inquietação por parte dos autores, traduzida pela aparente antinomia entre o Decreto 5.450, de 31 de maio de 2005, que regulamenta o pregão eletrônico, e o Decreto 8.538, de 06 de outubro de 2015, que traz como objetivo precípuo aos benefícios concedidos às MEs e EPPs nas licitações de promover o desenvolvimento econômico e social no âmbito local e regional.

O Decreto n 5.450/05 obriga, nas licitações da administração pública federal, a utilização da modalidade licitatória do pregão para aquisição de bens e serviços comuns, com preferência para a forma eletrônica, salvo nos casos de comprovada inviabilidade (técnica ou operacional), a ser justificada pela autoridade competente (Brasil, 2005).

Sendo assim, o sentido do Decreto $n^{\circ} 5.450 / 05$ é o de estimular a participação do maior número de fornecedores. Contudo, esse propósito confronta com o objetivo do Decreto $8.538 / 15$, no que diz respeito à promoção do desenvolvimento econômico e social no âmbito do município ou da região. Ora, o administrador público federal deparase, a todo momento, com a obrigatoriedade de utilizar o formato eletrônico do pregão, com o fim de universalizar o acesso à licitação, mas ao mesmo tempo, deve ater-se ao desenvolvimento econômico e social no âmbito municipal e regional, nas licitações em que se assegure tratamento privilegiado às MEs e EPPs. Nas compras públicas federais, portanto, o atendimento ao disposto no Decreto 8.538/15 fica prejudicado, tendo em vista a obrigatoriedade de se conceder ampla participação às empresas sediadas em todo o território nacional.

Posto isso, percebe-se que o próprio legislador deixou lacunas ao conceder as prerrogativas às MPEs, o que pode ser considerado, além de outros fatores já mencionados (Cabral et al., 2015; Carneiro, 2017; Fee et al., 2002; Karjalainen, \& Kemppainen, 2008; Reis, \& Cabral, 2015), um aspecto decisivo na motivação desse segmento de empresas em participar dos processos licitatórios promovidos por órgãos da administração pública.

Aprofundando ainda mais a discussão, é importante destacar o Projeto de Lei 368/2011, do deputado federal Marçal Filho, como tentativa de resolução à contradição expressa na legislação vigente. Tal projeto objetivou alterar o texto do Art. $3^{\circ}$ da Lei 
8.666/93, incluindo a possibilidade de preferência a produtos e serviços locais e regionais nos certames licitatórios governamentais. No entanto, em 2013 o projeto foi rejeitado e arquivado, com a justificativa de que seu teor é contrário ao disposto no inciso I do $\S 1^{\circ}$ do art. $3^{\circ}$ da mesma Lei, o qual veda "cláusulas ou condições que comprometam, restrinjam ou frustrem o seu caráter competitivo, e estabeleçam preferências ou distinções em razão da naturalidade, da sede ou domicílio dos licitantes ou de qualquer outra circunstância" (grifos nossos) (Brasil, 1993). Aqui, mais uma vez, surge o debate jurídico acerca da antinomia expressa pelo conflito entre normas que regulamentam a mesma matéria. No entanto, tal discussão vai além do objetivo deste estudo.

Vale destacar a dificuldade em aplicar as políticas de desenvolvimento para MPEs diante do regime jurídico-administrativo rígido e burocrático que norteia as contratações públicas. A todo o momento, os debates giram em torno de leis e procedimentos, reafirmando o entendimento de Fiuza (2009) e Motta (2010) acerca do caráter formal das normas que regem as licitações brasileiras, o que prejudica qualquer outra dimensão que se queira perseguir em termos de eficiência, ou ainda na tentativa de inclusão de políticas públicas econômicas e sociais.

\section{CONSIDERAÇÕES FINAIS}

O objetivo do presente estudo foi analisar a influência das MEs e EPPs locais/regionais nos certames licitatórios de uma IFES localizada no interior de Minas Gerais, no período de 2015 a 2017. Para tanto, foi verificado o universo das MEs e EPPs homologadas nos pregões eletrônicos realizados pela IFES pesquisada, durante 0 período. Foi recortado deste universo, as MEs e EPPs localizadas na microrregião onde está situada a universidade lócus do estudo.

Conforme demonstrado, várias são as iniciativas promovidas pelo Estado a fim de priorizar o desenvolvimento e fortalecimento da economia nacional, desde as preferências estabelecidas pela $\mathrm{CF} / 88$ até a promulgação de leis e decretos infraconstitucionais específicos, com o intuito de melhorar a situação econômica, especialmente das MPEs, inclusive no que se refere ao acesso ao mercado de aquisições públicas, tendo em vista sua contribuição para a sociedade na geração de emprego e renda (Freitas, 2011; Jacoby Fernandes, 2017; SEBRAE, 2014).

Contudo, verificou-se a partir do alcance dos objetivos propostos que, apesar de ter ocorrido um aumento significativo do número de MPEs contratando com a administração pública, a influência de ME e EPP locais/regionais nos pregões eletrônicos promovidos 
pela IFES investigada ainda mostra-se tímida, quando comparada ao universo das licitações do órgão, não alcançando 1\% de representatividade.

A realidade apresentada mostra que, apesar de existir um mercado potencial para a atuação de MPEs locais e regionais (Freitas, 2011; Jacoby Fernandes, 2017; SEBRAE, 2014), o que se vislumbra é a dificuldade de garantir, na prática, a efetivação das ferramentas criadas pelo Estado, a fim de promover o incremento desse segmento nas contratações públicas.

Ademais, foi trazido à discussão algumas lacunas a serem preenchidas por parte da legislação que trata da temática, tendo em vista a dificuldade percebida na aplicação dos benefícios às MEs e EPPs nas aquisições públicas. Um exemplo é a contradição aparente entre os dispositivos do Decreto do pregão eletrônico, 5.450/05, e o Decreto 8.538/15, que regulamenta o tratamento favorecido, diferenciado e simplificado para as MPEs nas licitações no âmbito da administração púbica federal.

Frente ao exposto, percebe-se que, além dos desafios encontrados pelas MPEs, no que tange à competitividade e outros aspectos relacionados ao tratamento favorecido dado a esse segmento, tem-se ainda os aspectos legais, contemplados pela rigidez normativa que rege as contratações públicas, os quais podem dificultar ou até mesmo impedir que a política de desenvolvimento econômico e social seja implementada a contento.

Conclui-se, portanto, que a utilização de licitação como instrumento de política pública é mais complexa do que apenas estabelecer como objetivo a "[...] promoção do desenvolvimento econômico e social no âmbito regional e local" (Brasil, 2015), conforme dispõe a legislação que concede prerrogativas às MPEs nas aquisições públicas. É preciso avançar muito na discussão acerca da utilização do poder de compra do Estado como potencial indutor de desenvolvimento regional. A reflexão que se propõe é se a licitação pública é a ferramenta mais adequada para se alcançar esse objetivo. Cumpre ressaltar que o presente estudo apresenta implicações para a prática, uma vez que, a partir dos resultados obtidos, pode-se contribuir para que todas as partes envolvidas (MPEs, legisladores e organizações públicas contratantes) promovam uma melhor adequação dos mecanismos de incentivos para a participação das MPEs nos certames.

Apontamos como sugestões para estudos futuros, a análise das possíveis causas da baixa adesão de fornecedores locais nos certames da IFES investigada, aplicando-se questionários e/ou entrevistas a representantes de MPEs sediadas no município onde está situada a universidade, a fim de verificar os desafios enfrentados por esse segmento de empresas nos certames licitatórios promovidos pela administração pública. 


\section{REFERÊNCIAS}

Arantes, R. (2006). Comercialização no mercado interno e compras governamentais. In: Conferência Brasileira Sobre Arranjos Produtivos Locais. 2 $2^{\underline{a}}$ Conferência Brasileira sobre Arranjos Produtivos Locais. Ministério do Planejamento, Orçamento e Gestão. Rio de Janeiro, RJ, Brasil. Disponível em: <http//desenvolvimento.gov.br/arquivos/dwnl1199710858.pdf>. Acesso em: 15 fev. 2018.

Araújo, H. R. (2011). Metas entre Estado e Mercado nas compras públicas. (Dissertação de Mestrado). Universidade Presbiteriana Mackenzie, São Paulo, SP, Brasil. Disponível em: $<$ http://up.mackenzie.br/fileadmin/user_upload/_imported/fileadmin/PUBLIC/UP_MACKENZIE/ser vicos_educacionais/stricto_sensu/Direito_Politico_Economico/Helena_Romeiro_de_Araujo.pdf>. Acesso em: 22 jul. 2018.

Auriol, E. (2006). Corruption in procurement and public purchase. International Journal of Industrial Organization, pp. 867-885. Disponível em: $<$ http://idei.fr/sites/default/files/medias/doc/by/auriol/corruption.pdf>. Acesso em: 16 out. 2017.

Baradel, E. M. (2011). Licitação como instrumento de política pública de desenvolvimento regional. (Dissertação de Mestrado). Escola de Administração de Empresas de São Paulo, São Paulo, SP, Brasil. Disponível em: <https://bibliotecadigital.fgv.br/dspace/handle/10438/9241>. Acesso em: 12 sgo. 2017.

$\begin{array}{ccc}\text { Brasil. (2017a). Ministério do Planejamento, Desenvolvimento e Gestão. Painel de Compras } \\ \text { do Governo } \quad \text { Federal. } & \text { Brasília. } & \text { Disponível }\end{array}$ $<$ https://www.comprasgovernamentais.gov.br/index.php/painel-de-compras-de-governo>. Acesso em: 20 ago. 2018.

(2017b). SISG - Sistema de Serviços Gerais. ComprasGovernamentais - Portal de compras do Governo Federal. Brasília. Departamento de Logística e Serviços Gerais, Ministério do Planejamento, Desenvolvimento e Gestão. Disponível em: <https://www.comprasgovernamentais.gov.br/index.php/sisg>. Acesso em: 12 ago. 2018.

(2017c). Ministério do Planejamento, Desenvolvimento e Gestão. Instituto Brasileiro de Geografia e Estatística - IBGE. Divisão regional do Brasil em regiões geográficas imediatas e regiões geográficas intermediárias. Coordenação de Geografia. Rio de Janeiro. 82p. Disponível em: <https://www.ibge.gov.br/geociencias-novoportal/cartas-e-mapas/redesgeograficas/15778-divisoes-regionais-do-brasil.html?\&t=acesso-ao-produto >. Acesso em: 13 ago. 2018.

(2015). Decreto 8.538, de 06 de outubro de 2015. Regulamenta o tratamento favorecido, diferenciado e simplificado para as microempresas, empresas de pequeno porte, agricultores familiares, produtores rurais pessoa física, microempreendedores individuais e sociedades cooperativas de consumo nas contratações públicas de bens, serviços e obras no âmbito da administração pública federal. Brasília. Disponível em: <http://www.planalto.gov.br/ccivil_03/_ato2015-2018/2015/decreto/d8538.htm>. Acesso em: 12 ago. 2018.

. (2014). Ministério do Planejamento. Informações Gerenciais de Contratações e Compras Públicas. Brasília. Disponível em: <http://www.comprasnet.gov.br/ajuda/01__resultados_gerais.pdf>. Acesso em: 23 jul. 2018.

(2006). Lei Complementar no 123, de 14 de dezembro de 2006. Institui o Estatuto Nacional da Microempresa e da Empresa de Pequeno Porte; altera dispositivos das Leis no 8.212 e 8.213, ambas de 24 de julho de 1991, da Consolidação das Leis do Trabalho - CLT, aprovada pelo Decreto-Lei no5.452, de 10 de maio de 1943, da Lei no 10.189, de 14 de fevereiro de 2001, da Lei Complementar no 63, de 11 de janeiro de 1990; e revoga as Leis no 9.317, de 5 
de dezembro de 1996, e 9.841, de 5 de outubro de 1999. Brasília. Disponível em: <http://www.planalto.gov.br/ccivil_03/leis/LCP/Lcp123.htm>. Acesso em: 5 mar. 2018.

(2005). Decreto $n^{\circ} 5.450$, de 31 de maio de 2005. Regulamenta o pregão, na forma eletrônica, para aquisição de bens e serviços comuns, e dá outras providências. Brasília. Disponível em:

<http://www.comprasnet.gov.br/legislacao/decretos/de5450_2005.html>. Acesso em: 10 mar. 2018 .

(1993). Lei no 8.666, de 21 de junho de 1993. Regulamenta o art. 37, XXI da Constituição Federal, institui normas para licitações e contratos da administração pública e dá outras providências. Brasília. Disponível em: <http://www.planalto.gov.br/ccivil_03/leis/L8666cons.htm>. Acesso em: 10 mar. 2018.

(1988). Constituição da República Federativa do Brasil de 1988. Brasília. Disponível em: <http://www.planalto.gov.br/ccivil_03/constituicao/constituicao.htm>. Acesso em: 15 jun. 2018.

Cabral, S., Reis, P. R. C., \& Sampaio, A. H. (2015). Determinantes da participação e sucesso das micro e pequenas empresas em compras públicas: uma análise empírica. Revista de Administração, São Paulo, v. 50(4), pp. 477-491. Disponível em: $<$ http://www.scielo.br/pdf/rausp/v50n4/0080-2107-rausp-50-04-0477.pdf>. Acesso em: 10 set. 2017.

Câmara, L. M., \& Frossard, L. B. D. M. (2010). Poder de compras da administração pública federal: novas perspectivas para o debate acadêmico. Encontro de Administração Pública e Governança, Vitória, ES, Brasil. v. 4, pp. 2-16. Disponível em: <http://www.anpad.org.br/admin/pdf/enapg393.pdf>. Acesso em: 20 set. 2017.

Carneiro, M. C. (2017). Dificuldades encontradas pelas micro e pequenas empresas na participação em licitações públicas das universidades federais de ensino superior. (Dissertação de Mestrado). Faculdade Campo Limpo Paulista - FACCAMP, Campo Limpo Paulista, SP, Brasil.

$<$ http://www.faccamp.br/new/arq/pdf/mestrado/Documentos/producao_discente/MartaCybeleCarn eiro.pdf>. Acesso em: 21 set. 2018.

Clark III, M., \& Moutray, C. M. (2004). The future of small businesses in the US federal government market place. Journal of Public Procurement, Highland Beach, v. 4(3), pp. 450-470. Disponível em:

<https://www.emeraldinsight.com/doi/abs/10.1108/JOPP-04-03-2004-B006>. Acesso em: 22 ago. 2017.

Dimitri, N., Piga, G., \& Spagnolo. (2006). Handbook of procurement. Cambridge University Press. Disponível em:

<ftp://nozdr.ru/biblio/kolxo3/G/GU/Dimitri\%20N.,\%20Piga\%20G.,\%20Spagnolo\%20G.\%20(eds.) $\% 20 H a n d b o o k \% 20$ of\%20procurement\%20(CUP,\%202006)(ISBN\%200521870739)(O)(562s)_GU _.pdf>. Acesso em: 12 set. 2017.

Fee, R., Erridge, A., \& Hennigan, S. (2002). SMEs and government purchasing in Northern Ireland: Problems and opportunities. European Business Review, v. 14(5), pp. 326-334. Disponível em:

<https://www.emeraldinsight.com/doi/abs/10.1108/09555340210444176>. Acesso em: 12 jul. 2017.

Fiuza, E. P. S. (2009). Licitações e governança de contratos: a visão dos economistas. In: Salgado, L. H.; Fiuza, E. P. S. (Orgs.). Marcos regulatórios no Brasil: é tempo de rever regras? 
Brasília: Ipea, 2009. v. 2. pp. 239-274. Disponível em: <http://www.ipea.gov.br/portal/images/stories/15_Livro_completo.pdf>. Acesso em: 20 set. 2017.

Fonseca, I. C. M., \& Mota, N. M. (2016). O acesso das Pequenas e Médias Empresas ao mercado dos contratos públicos: algumas soluções. In: A transposição das diretivas Europeias de 2014 e o Código dos Contratos Públicos. Lisboa: Faculdade de Direito da Universidade de Lisboa, 96p. Disponível em: <https://www.icjp.pt/sites/default/files/publicacoes/files/ebook_diretivaseuropeias2014eccp_icjp-cidp_0.pdf>. Acesso em: 12 ago. 2018.

Freitas, J. (2011). Sustentabilidade: direito ao futuro. Belo Horizonte: Fórum.

Gansler, J. S., Lucyshyn, W., \& Ross, K. M. (2003). Digitally Integrating the Government Supply Chain: E-Procurement, E-Finance, and E-Logistics. Washington: IBM Center for The Business of Government (E-Government Series). Disponível em: $<$ https://www.researchgate.net/publication/228745696_Digitally_Integrating_the_Government_Su pply_Chain_E-Procurement_E-Finance_and_E-Logistics>. Acesso em: 22 set. 2017.

Jacoby Fernandes, J. U. (2017). O governo contratando com a Micro e Pequena Empresa: o estatuto da Micro e Pequena Empresa fomentando a economia do país. Brasília: SEBRAE, 2017. 196p. Disponível em: <http://www.bibliotecas.sebrae.com.br/chronus/ARQUIVOS_CHRONUS/bds/bds.nsf/965e9409d9 3647cb97f0702e3017995d/\$File/7770.pdf>. Acesso em: 5 abr. 2018.

Karjalainen, K., \& Kemppainen, K. (2008). The involvement of small- and medium-sized enterprizes in public procurement: Impact of resource perceptions, eletronic systems and enterprise size. Journal of Purchasing \& Supply Management, v. 14(4), pp. 230-240. Disponível em:

<https://www.sciencedirect.com/science/article/pii/S1478409208000642>. Acesso em: 12 abr. 2017.

Kureski, R., \& Rolim, C. F. C. (2009). Impacto econômico de curto prazo das universidades federais na economia brasileira. Revista Paranaense de Desenvolvimento, v. 117, pp. 29-51. Disponível em: <http://www.ipardes.pr.gov.br/ojs/index.php/revistaparanaense/article/view/407>. Acesso em: 11 ago. 2018.

Moreira, H. C., \& Morais, J. M. (2003). Compras Governamentais - Políticas e Procedimentos na Organização Mundial de Comércio, União Europeia, Nafta, Estados Unidos e Brasil. Brasília: Ipea. (Texto para Discussão, n. 0930, CEPAL - SERIE estudios y perspectivas). Disponível em: $<$ http://repository.eclac.org/bitstream/handle/11362/4830/S036392_fr.pdf?sequence=1\&isAllowed $=\mathrm{y}>$. Acesso em: 13 set. 2017.

Motta, A. R. (2010). O combate ao desperdício no gasto público: Uma reflexão baseada na comparação entre os sistemas de compra privado, público federal norte americano e brasileiro. (Dissertação de Mestrado). Instituto de Economia, Universidade Estadual de Campinas, Campinas, SP, Brasil. Disponível em: <http://repositorio.unicamp.br/jspui/handle/REPOSIP/285965>. Acesso em: 21 out. 2017.

OECD. (2017). Government at a Glance 2017. OECD Publishing, Paris: 2017. Disponível em: <https://www.oecd.org/gov/government-at-a-glance-2017-highlights-en.pdf>. Acesso em: 10 out. 2018.

OECD. (2002). Government Procurement: A Synthesis Report. OECD Journal on Budgeting, v. 2(3). Disponível em:

<https://www.oecd.org/gov/budgeting/43506020.pdf>. Acesso em: 10 set. 2017. 
Oliveira, C. A. L. (2015). Compras públicas no âmbito federal nos Estados Unidos da América. Análise sucinta acerca das principais modalidades de compras de bens e serviços, bem como dos principais instrumentos contratuais decorrentes ou antecedentes. Revista de Doutrina da 4 $4^{a}$ Região, Porto Alegre, n. 67. Disponível em: <http://www.revistadoutrina.trf4.jus.br/artigos/edicao067/Christiaan_deOliveira.html>. Acesso em: 21 out. 2017.

Ouverney, A. M. (2005). Relações Estado, sociedade e mercado subjacentes aos padrões de organização estatal e o futuro da reforma administrativa. Cad. EBAPE.BR, Rio de Janeiro, v. 3(2), pp. 01-06. Disponível em: $<$ http://www.scielo.br/scielo.php?script=sci_arttext\&pid=S167939512005000200013\&lng=en\&nrm =iso>. Acesso em: 23 fev. 2017.

Reis, P. R. C., \& Cabral, S. (2015). Public procurement strategy: The impacts of a preference programme for small and micro businesses. Public Money \& Management, v. 35(2), pp. 103-110. Disponível em:

<https://www.tandfonline.com/doi/abs/10.1080/09540962.2015.1007704>. Acesso em: 21 mar. 2018.

Sampieri, R. H., Collado, C. F., \& Lucio, P. B. (2013). Metodologia de pesquisa. 5. ed. Porto Alegre: Penso.

SEBRAE. (2014). Serviço Brasileiro de Apoio às Micro e Pequenas Empresas. Participação das Micro e Pequenas Empresas na Economia Brasileira. Brasília: (c) 2014 Serviço Brasileiro de Apoio às Micro e Pequenas Empresas - Sebrae. Disponível em:

$<$ http://www.sebrae.com.br/Sebrae/Portal\%20Sebrae/Estudos\%20e\%20Pesquisas/Participacao \%20das\%20micro\%20e\%20pequenas\%20empresas.pdf>. Acesso em: 12 mar. 2018.

Silva, E. P. (2008). O uso do Poder de Compra do Estado como Instrumento de Política Pública: A Lei no 123/2006, sua implementação. (Dissertação de Mestrado). Fundação Getúlio Vargas, Rio de Janeiro, RJ, Brasil. Disponível em: <http://bibliotecadigital.fgv.br/dspace/handle/10438/3408>. Acesso em: 10 abr. 2017.

Sousa Junior, C. C. (2008). Utilização do poder de compra do Estado de Minas Gerais como instrumento de desenvolvimento regional e para promoção de políticas públicas locais redistributivas. Anais do XIII Seminário sobre Economia Mineira - UFMG. Belo Horizonte, Minas Gerais, Brasil. Disponível em: <http://diamantina.cedeplar.ufmg.br/portal/download/diamantina2008/D08A145.pdf>. Acesso em: 11 mar. 2017.

Theóphilo, C. R., \& Martins, G. A. (2009). Metodologia da investigação científica para ciências sociais aplicadas. 2. ed. São Paulo: Atlas.

Torres, N. T. (2012). Compras Governamentais: Proposta de um modelo multicriterial para licitações públicas. (Tese de Doutorado). Universidade Federal do Rio de Janeiro, Rio de Janeiro, RJ, Brasil. Disponível em: <http://objdig.ufrj.br/60/teses/coppe_d/NilsonTrevisanTorres.pdf>. Acesso em: 27 jun. 2017.

União Europeia. (2014). DIRETIVA 2014/24/UE DO PARLAMENTO EUROPEU E DO CONSELHO de 26 de fevereiro de 2014, relativa aos contratos públicos e que revoga a Diretiva 2004/18/CE. Jornal Oficial da União Europeia. L 94/65-242. Estrasburgo. Disponível em: $<$ https://eur-lex.europa.eu/legal-content/PT/TXT/?uri=celex\%3A32014L0024>. Acesso em: 20 fev. 2018.

United States. (2005). GENERAL SERVICES ADMINISTRATION. Federal Acquisition Regulation. Washington D.C. Disponível em: <https://www.acquisition.gov/browsefar>. Acesso em: 13 fev. 2017. 
Vacca, G. (1991). Estado e Mercado, Público e Privado. Lua Nova, s/v, n. 24, pp.150-164. Disponível em: <http://www.scielo.br/pdf/In/n24/a08n24.pdf>. Acesso em: 13 mai. 2018.

World Bank. (2004). Brazil: Country Procurement Assessment Report. Washington, DC. (C) World Bank. Disponível em:

<https://openknowledge.worldbank.org/handle/10986/14590>. Acesso em: 11 mai. 2017.

Para citar este artigo:

Chaves, F., Bertassi, A., \& Silva, G. (2019). Compras Públicas e Desenvolvimento Local: Micro e Pequenas Empresas Locais nas Licitações de uma Universidade Pública Mineira. REGEPE Revista de Empreendedorismo e Gestão de Pequenas Empresas, 8(1), 77-101. doi:https://doi.org/10.14211/regepe.v8i1.867 